\title{
Potential contribution of fish restocking to the recovery of deteriorated coral reefs: an alternative restoration method?
}

Uri Obolski, Lilach Hadany, Avigdor Abelson

Counteracting the worldwide trend of coral reef degeneration is a major challenge for the scientific community. A crucial management approach to minimizing stress effects on healthy reefs and helping the recovery of disturbed reefs is reef protection. However, the current rapid decline of the world's reefs suggests that protection might be insufficient as a viable stand-alone management approach for some reefs. We thus suggest that the ecological restoration of coral reefs (CRR) should be considered as a valid component of coral reef management, in addition to protection, if the applied method is economically applicable and scalable. This theoretical study examines the potential applicability and outcomes of restocking grazers as a restoration tool for coral reef recovery - a tool that has not been applied so far in reef restoration projects. We studied the effect of restocking grazing fish as a restoration method using a mathematical model of degrading reefs, and analyzed the financial outcomes of the restocking intervention. The results suggest that applying this restoration method, in addition to protection, can facilitate reef recovery. Moreover, our analysis suggests that the restocking approach almost always becomes profitable within several years. Considering the relatively low cost of this restoration approach and the feasibility of mass production of herbivorous fish, we suggest that this approach should be considered and examined as an additional viable restoration tool for coral reefs. 
1 Potential contribution of fish restocking to the recovery of deteriorated coral

2

3

4

5

6

7

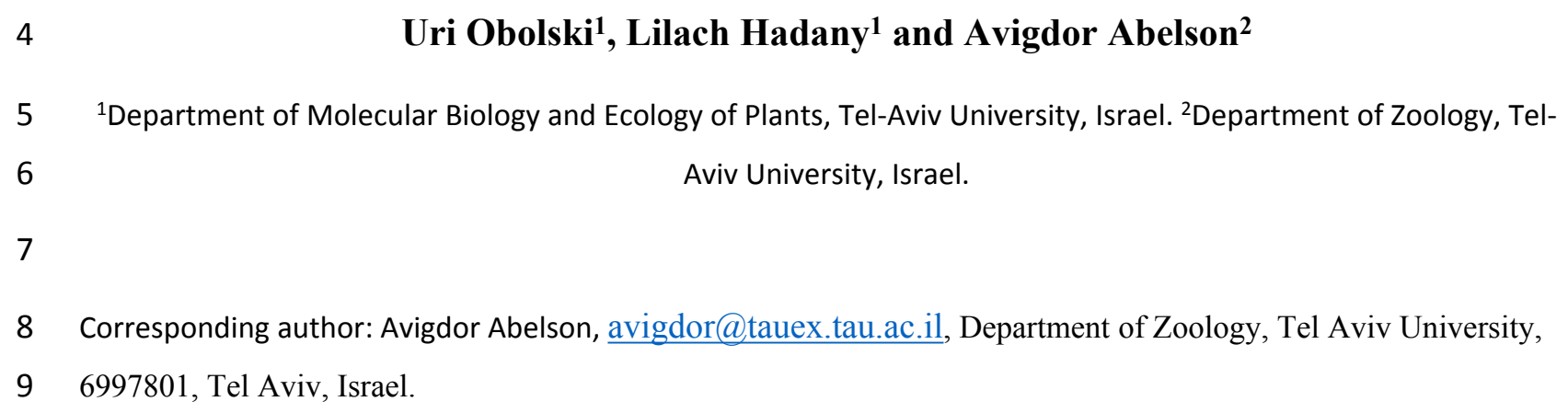

8 Corresponding author: Avigdor Abelson, avigdor@tauex.tau.ac.il, Department of Zoology, Tel Aviv University, 9 6997801, Tel Aviv, Israel. reefs: an alternative restoration method? 


\section{Abstract}

13 Counteracting the worldwide trend of coral reef degeneration is a major challenge for the

14 scientific community. A crucial management approach to minimizing stress effects on healthy reefs and helping the recovery of disturbed reefs is reef protection. However, the current rapid decline of the world's reefs suggests that protection might be insufficient as a viable stand-alone management approach for some reefs. We thus suggest that the ecological restoration of coral reefs (CRR) should be considered as a valid component of coral reef management, in addition to protection, if the applied method is economically applicable and scalable.

This theoretical study examines the potential applicability and outcomes of restocking grazers as a restoration tool for coral reef recovery - a tool that has not been applied so far in reef restoration projects. We studied the effect of restocking grazing fish as a restoration method using a mathematical model of degrading reefs, and analyzed the financial outcomes of the restocking intervention. The results suggest that applying this restoration method, in addition to protection, can facilitate reef recovery. Moreover, our analysis suggests that the restocking approach almost always becomes profitable within several years. Considering the relatively low cost of this restoration approach and the feasibility of mass production of herbivorous fish, we suggest that this approach should be considered and examined as an additional viable restoration tool for coral reefs. 


\section{Introduction}

32 Coral reefs are considered to be among the most threatened and fastest deteriorating marine

33 ecosystems (Burke 2011; Knowlton \& Jackson 2008). At present, a well-accepted approach to

34 countermeasure reef decline is that of 'conservation', which focuses on the protection of reefs

35 from overuse and misuse (e.g. over-fishing and destructive fishing), and the removal of local

36 stressors, if such exist (Hughes et al. 2010; Mumby \& Steneck 2008). Nonetheless, coral reef

37 degeneration has remained a major challenge for the scientific community (Hughes et al. 2010),

38 and the present conservation-based approach seems insufficient to serve as a stand-alone

39 solution.

40 An alternative approach, aimed at targeting this challenge, is coral reef restoration (CRR; also termed coral reef rehabilitation" Edwards \& Gomez 2007; Rinkevich 2005). The common 'CRR approach' posits promoting the recovery of reefs mainly through coral reef gardening: the transplantation of stony corals, much in the way that nursery stock is planted in terrestrial gardens (Edwards 2010; Edwards \& Gomez 2007; Rinkevich 2005). At present, however, CRR remains a subject of controversy in the coral reef research community. The major arguments against CRR include its limited scalability (Adger et al. 2005; Mumby \& Steneck 2008); the ineffectiveness of restoration efforts in the face of natural threats, such as climate change and ocean acidification (De'ath et al. 2009; Mumby \& Steneck 2008; Pandolfi et al. 2003); and the high costs of the prevailing CRR approaches, i.e. reef gardening and artificial reefs (Adger et al. 2005; Mumby \& Steneck 2008). Much of the criticism of the restoration approach stems from

51 the view that CRR, in its present state, is practically limited to a single method, i.e. coral reef

52 gardening, which is currently attracting the major efforts of restoration interventions and

53 scientific research (Edwards 2010; Edwards \& Gomez 2007; Rinkevich 2008). 
54 In the present study we propose the approach of restocking grazing fish as an additional CRR

55

56

57

58

method, and examine its possible efficiency and economic value. Restocking (also termed reintroduction or biomanipulation of fish populations; Angeler 2010; Cowx 1999) is a common tool in the applied management of non-marine aquatic ecosystems, aimed at restoring water quality and vegetation characteristics (Angeler 2010; Cowx 1999; Cowx \& Gerdeaux 2004). Although less used in the marine environment, restocking has recently been applied to coastal marine ecosystems, mainly as a fishery management tool aimed at recovering the yields of target commercial fish populations (Leber 2013; Lindegren et al. 2010; Lorenzen et al. 2013; Lorenzen et al. 2010). Moreover, there have been some attempts at restocking in coral reefs, mostly of invertebrate species (e.g. the grazing gastropod Trochus sp.; Castell et al. 1996; Villanueva et al. 2010), but also fish stock enhancement (e.g. rabbitfish and parrotfish; Bowling 2014).

Restocking of grazing fish in coral reefs is based on the following rationale: Most degraded reefs undergo a phase-shift from coral-dominated reefs to algal-dominated ones (mostly macroalgae, or algal turfs). Such degraded reefs are likely to remain in their unfavorable state if not inhabited by enough grazers. Since the natural recovery of grazing fish is very likely to take years (or even decades; Blackwood et al. 2012), stock enhancement of key grazing species is expected to significantly accelerate the process. Given that stock enhancement has been successful in other marine systems (e.g. kelp forests and rocky coastal habitats), and that the technologies for culturing some species of grazing fish already exist (Bowling 2014; Duray 1998), a restoration approach based on stock enhancement seems to be worth examination.

To examine the possible ecological outcomes and economic feasibility of restocking grazing fish as a potential restoration tool for degraded reefs, we: 1) applied reef dynamic models (Blackwood et al. 2011; Blackwood et al. 2012; Mumby et al. 2007) to compare recovery rates 
77 under various conditions of conservation and restoration; and 2) performed a cost-benefit

78 analysis to compare the financial implications of restocking over time according to the model;

79 that is to determine whether some of the limited funds available for reef conservation should be

80 allocated to restoration or rather solely to conservation.

81

82

83

84

85 


\section{Methods}

\section{The Model}

88 We examine the potential outcomes of fish restocking using modifications of mathematical

89

$106 \frac{\mathrm{dM}}{\mathrm{dt}}=\mathrm{aMC}-\frac{\mathrm{g}(\mathrm{P}) \mathrm{M}}{\mathrm{M}+\mathrm{T}}+\gamma \mathrm{MT}$

$107 \frac{\mathrm{dC}}{\mathrm{dt}}=\mathrm{rTC}-\mathrm{dC}-\mathrm{aMC}$ 
$108 \frac{\mathrm{dT}}{\mathrm{dt}}=\frac{\mathrm{g}(\mathrm{P}) \mathrm{M}}{\mathrm{M}+\mathrm{T}}-\gamma \mathrm{MT}-\mathrm{rTC}+\mathrm{dC}$

$109 \frac{\mathrm{dP}}{\mathrm{dt}}=\mathrm{sP}\left(1-\frac{\mathrm{P}}{\mathrm{K}(\mathrm{M}+\mathrm{T}, \mathrm{R})}\right)-\mathrm{mP}-f \mathrm{P}$

$110 \frac{\mathrm{dR}}{\mathrm{dt}}=\mathrm{H}_{\mathrm{g}} \mathrm{C}(3-\mathrm{R})-\mathrm{H}_{\mathrm{e}}(1-\mathrm{C})(\mathrm{R}-1)$

111 We assume that corals grow on a seabed covered with algal turfs at rate $r$, die of natural causes at

112 rate $d$, and are covered by macroalgae at rate $a$. Macroalgae too grow over algal turfs, at rate $\gamma$.

113 Grazing fish grow according to the logistic growth equation, with growth rate s, and a maximal

114 carrying capacity function $K(M+T, R)$, which is the product of a linear, increasing, function of

115 rugosity and a Hill-Langmuir function of $M+T$ (for details see Blackwood et al. 2011). The

116 grazing fish graze macroalgae into algal turfs at a rate $\frac{\mathrm{g}(\mathrm{P}) \mathrm{M}}{\mathrm{M}+\mathrm{T}}$, where $g(P)$ is taken to be $P$.

117 Thus, the grazing fish reduce the rate of macroalgae growth over corals, while simultaneously

118 expanding algal turfs, which can provide seabed for coral growth (Jompa \& McCook 2002).

119 Grazing fish are fished at rate $f$.

120 Terrain rugosity increases due to growth of corals, $h_{G}$, and decreases due to bioerosion at a rate

$121 h_{E}$, where both $h_{G}$ and $h_{E}$ depend on current rugosity and coral coverage (functions were

122 estimated from data by Blackwood et al. 2011). Grazing fish migrate from the reef at rate $\mathrm{m}$. The

123 parameter values and their meanings are given at Table 1. All parameter values used are taken

124 from (Blackwood et al. 2011), except for spillover estimates (m). We used spillover rates

125 estimated in (Kaunda-Arara \& Rose 2004) (acquired by the tag and release method) and

126 converted them to yearly migration rates assuming an exponential decrease, in order for them to 
127 fit the parametrization of our equations (see Text S1). We first consider the effect of restocking

128 on a single reef, and then extend the model to two reefs, each represented by the system of

129 differential equations presented above. The reefs are coupled by the migration parameter. We

130 assume that all fish from one reef, denoted Reef I, migrate to another reef, denoted Reef II; while

131 fish from Reef II migrate as in the one reef system, and are effectively lost in our model. This is

132 a conservative assumption, as we examine the worst case in terms of restocking benefit in which

133 none of the fish from Reef II migrate to Reef I. Additionally, we assume that both reefs are

134 relatively close, so that climatic or anthropogenic perturbations will affect both reefs similarly

135 and bring them to the same initial conditions (a distance of $\sim 10 \mathrm{~km}$ might be an estimate for such

136 conditions; Hughes et al. 1999). We introduce restocking by adding an amount $\delta_{\mathrm{P}}$ to the initial

137 value of $P$, namely $P_{0}$. Since $P$ is normalized to be between 0 (no grazers) and 1 (maximal

138 capacity of grazers), $\delta_{\mathrm{P}}$ is given as a fraction of the maximal abundance of grazing fish possible

139 in the modeled habitat.

140 We model the economic impact of fish restocking using a cost-benefit analysis. We define $\mathrm{X}$ as

141 the size of the coral reef in $\mathrm{km}^{2} ; \mathrm{B}_{\mathrm{C}}$ is the revenue, per $\mathrm{km}^{2}$ per year, resulting from coral

142 coverage (excluding revenue from fishing); $\hat{\mathrm{K}}$ is the maximal carrying capacity of the restocked

143 grazer fish per $\mathrm{km}^{2}$, and $r^{\prime}$ is the economic discount rate. For $t$ years, the difference in revenue

144 for a coral reef with restocking versus a reef with no intervention can be estimated by (also

145 known as the net present value):

$146 \quad(\mathrm{E} 2)$

147

$\operatorname{Revenue}(t)=\mathrm{X} \cdot \mathrm{B}_{\mathrm{C}} \cdot \Sigma_{\mathrm{i}=0}^{\mathrm{t}}\left(1+\mathrm{r}^{\prime}\right)^{-\mathrm{i}}\left(\mathrm{C}^{\mathrm{re}}(\mathrm{i})-\mathrm{C}^{\mathrm{no}}(\mathrm{i})\right)-\left(\& \hat{\mathrm{K}} \cdot \mathrm{X} \cdot \delta_{\mathrm{P}}\right)$ 
148 where $C^{\text {re }}(\mathrm{i})$ and $C^{\text {no }}(i)$ are the coral coverages of reefs with and without restocking, at year $i$,

149 respectively. Simply put, we calculate the difference in coral coverage between a reef with and

150 without the restocking intervention. This difference is multiplied by the size of the reef and the

151 financial benefit for each squared kilometer of the reef. The term is discounted with regard to

152 inflation. Finally, the cost of restocking is subtracted. This is a conservative estimate, since in

153 this model restocking increases coral coverage, and it is assumed that the benefit from coral reefs

154 declines relative to the cost of the fish, due to discounting. The parameters and variables of the

155 economic model describing the revenue are given in Table 2. The Matlab code for all results is

156 given in supplementary file S3.

\section{Results}

\section{$158 \quad$ A single reef}

159 First, we examine the long-term effects of restocking for various initial conditions of the dynamic system presented above, with a single coral reef. We assume that as part of the restoration treatments, fishing restrictions are implemented, so that $f=0$ in all the following results. The state of a disturbed reef is represented by the initial conditions of the coral coverage (C) and macroalgae $(M)$ (determining the amount of algal turfs, as $T=1-M-C$ ). The revenue of restocking (derived from (E2)) as well as the final outcomes of the restocking intervention (derived from $(E 1)$ ), are presented as functions of the system's initial conditions in Fig.1. Since this dynamic system has two attractors, one of high coral coverage and the other of high macroalgae coverage (Blackwood et al. 2011), the range of initial conditions can be divided into 
170 without restocking; (II) areas wherein the system would reach a high macroalgae state in the

171 absence of intervention (but under fishing restrictions), but restocking would allow its return to

172 the high coral coverage state; and (III) areas where the system will reach a state with high

173 macroalgae coverage with or without restocking. These areas are denoted in Fig.1 as (I), (II) and

174 (III), respectively, and are separated by black borders. In addition, colors in Fig.1 represent the

175 expected revenue of restocking, 5 and 20 years after restocking has taken place, in $\log _{10}$ scale,

176 with negative revenue replaced by zeros (Fig.1, panels A and B). Note that the variables are

177 normalized to represent the entire reef area, so that $T=1-M-C$ and the state of the algal turfs $(T)$

178 is defined by the other two variables. The parameters used in Fig.1 for the dynamical system

179 were $\mathrm{P}_{0}=0.1, \delta_{\mathrm{P}}=0.1, \mathrm{R}_{0}=1.6$ (the rest of the dynamical system parameters were given the

180 values estimated in Blackwood et al. 2011). The spillover was estimated from odds of tagged

181 fish leaving and staying in the coral reefs (Kaunda-Arara \& Rose 2004), and was transformed to

182 a rate term to yield $\mathrm{m}=0.12$. The reef size $(\mathrm{X})$ was taken to be $15 \mathrm{~km}^{2}$, the estimated grazing

183 fish number per $\mathrm{km}^{2}(\hat{\mathrm{K}})$ was taken as 3000, estimated from (Gaudian et al. 1996), according to

184 the density of the most common fish in the examined coral reef (accounting for $64 \%$ of all fish).

185 Thus, when we enhance the number of grazing fish by $\delta_{\mathrm{P}}=0.1$, we de facto add 300 fish per

186 each $\mathrm{km}^{2}$ of reef area. The financial benefit from the coral reef $\left(\mathrm{B}_{\mathrm{C}}\right)$ was estimated from (Cesar

187 \& Van Beukering 2004), as 200,000 \$ per year per $\mathrm{km}^{2}$, which is a very conservative estimate

188 (see Spurgeon 1999, for example). The average cost of each fish, $\tilde{c}$, was estimated to be $20 \$$ as

189 an over-estimated price. This estimated cost is based on the recent average fish price for cultured

190 fish (ca. $1.8 \$ / \mathrm{kg}$ ) taken from fish price trends in real terms during the last two decades (FAO

191 2014). Estimating an average size of $500 \mathrm{gr}$ of released fish results in a cost of $\$ 0.9$ per fish. The

192 actual fish cost, however, should be calculated based on the expected survival rates of the 
193 released fish. Estimating a survival rate of at least 10\% of the released fish (Hervas et al. 2010),

194 implies a release of ca.10 times the size of the desired population size. Therefore, the realistic

195 (yet over-estimated) cost should be set at $\$ 10$ per fish, and to account for variance of estimates

196 we have multiplied this by a factor of 2 . Therefore, using our estimates, the cost of restocking a

197 reef spanning $15 \mathrm{~km}^{2}$ will amount to approximately $\& \hat{\mathrm{K}} \cdot \mathrm{X} \cdot \delta_{\mathrm{P}}=20 \cdot 3,000 \cdot 15 \cdot 0.1=90,000$

198 USD.

199 The discount rate $\left(r^{\prime}\right)$ was set to 0.05 , but our results remain robust when varying discount rates 200 (Text S2).

201 From Fig.1 we can see that restocking broadens the range of conditions under which the system

202 will reach a high coral coverage state, but not to a very substantial extent. However, restocking

203 increases the expected revenue of a disturbed reef under a wide range of initial conditions,

204 especially in the long term (Fig.1, compare A to B). This is the result of the relatively cheap cost

205 of restocking (estimated at 6000 USD per $\mathrm{km}^{2}$ ), combined with the high revenue of coral reef

206 area (estimated at 200,000 \$ per year per $\mathrm{km}^{2}$ ). Even if the reef does not restore to high coral

207 coverage, the delay in its deterioration, enabled by restocking, will still be profitable for a large

208 extent of the initial conditions. Similarly, even if the reef will eventually be restored without

209 human intervention, restocking will shorten the period of time required to achieve this. This is

210 shown in Fig.2, where a time series of the values of the coral coverage $(C)$, macroalgae coverage

$211(M)$, and grazing fish $(P)$ are plotted with and without restocking for two sets of initial

212 conditions. Fig.2A-B presents the model variables simulated from initial values corresponding to

213 area (I) in Fig.1 $\left(C_{0}=0.35, M_{0}=0.05\right)$, in which the reef will be restored without intervention.

214 Although both scenarios lead to an eventual high coral coverage, we can see that restocking will

215 shorten the time to equilibrium to about $65 \%$ of this time in a system without restocking 
216 (compare Fig.2A to Fig2.B). A change in initial conditions, to those corresponding to area II in

217 Fig.1, can change the dynamics entirely. Fig.2C-D represents initial conditions $\left(C_{0}=0.35\right.$,

$218 M_{0}=0.07$ ) in which the coral reef will deteriorate without intervention (Fig.2C), but will return to

219 high coral coverage when restocking is implemented (Fig.2D).

220 In area III, the reef would remain in a high macroalgae state with or without restocking. In such a

221 case, we could consider a combination of restoration methods. For instance, if feasible,

222 eradication of macroalgae will be expressed as moving left on the phase plane presented in Fig.1

223 in our model. We expect that when restocking is applied, the extent of eradication needed to

224 bring the system to a point where restoration will be possible will be lower, and the restoration

225 time from that point will be shorter.

\section{Multiple Reefs}

228 We next generalize the notion of restocking to a system consisting of two reefs, in which the fish

229 migrate from one reef to another. We define the direction of migration from Reef I (upstream) to

230 Reef II (downstream). Under this range of initial conditions we note five possible scenarios: (I)

231 initial conditions under which in both reefs the system reaches a state with high coral coverage

232 without restocking; (II) areas wherein one reef will reach high coral coverage without

233 intervention, while the other reef will only succeed if restocking is applied; (III) areas wherein

234 one reef will reach high coral coverage without intervention, while the other will reach the

235 macroalgae state even if restocking is applied; (IV) areas in which both reefs will deteriorate to

236 the macroalgae state without intervention, but restocking will salvage one of them; and (V) areas

237 in which both rates will deteriorate and restocking will not help either reef. These areas are

238 marked accordingly on Fig.3. Additionally, colors in Fig.3 represent the expected revenue of 
239 restocking 5 and 20 years after the restocking has taken place, in $\log _{10}$ scale, with negative

240 revenue replaced by zeros. Parameters of Fig.3 are as in Fig.1, with the migration from Reef I is

241 directed towards Reef II, and migration from Reef II is lost.

242 We can see that restocking broadens the range of conditions under which at least one of the reefs

243 will reach a high coral coverage state. Moreover, restocking increases the expected revenue from

244 the coral reefs under almost all conditions. This is due to the amplification of the effect seen in

245 Fig.1 and Fig.2. Even when restocking is only performed for one of the reefs, it accelerates the

246 return to a high coral coverage state, and delays deterioration of the reefs. Fig.4 presents time-

247 series examples for these dynamics for the same parameters as in Fig.2. $C_{I}, M_{I}, P_{I}$ and $C_{I I}, M_{I I}$,

$248 P_{I I}$, are the coral coverage, macroalgae coverage and grazing fish, for the upstream and

249 downstream reefs, respectively. We can see that restocking only the upstream reef can shorten

250 the recovery time to about 60 , for both the downstream and upstream reefs $\%$, relative to the

251 system without restocking (Fig.4 compare A to B). In addition, for parameters that are within

252 region II of Fig.3, restocking can salvage the upstream reef from deterioration (Fig.4 compare C 253 to D).

\section{Discussion}

257 Studies carried out in the last decade suggest that the protection of coral reefs as MPAs (Marine

258 Protected Areas) is a useful tool for the maintenance of coral cover (Selig \& Bruno 2010), reef

259 resilience, and recovery (Mumby \& Harborne 2010). However, most coral reefs around the

260 world have not been protected. Moreover many coral reefs are not in an optimal healthy state due 
261 to diverse stressors, mainly anthropogenic: e.g. over-fishing, habitat destruction, pollution, and

262 climate-change related effects (Burke 2011; De'ath et al. 2012). The question thus arises as to

263 what should be the appropriate management approaches in those numerous coral reefs that have

264 already become significantly degraded. A key concern is whether ad hock protection can serve as

265 a stand-alone tool to help in the natural recovery of these reefs, or might it not suffice

266 (Huntington et al. 2011). In the latter case, additional management approaches might be required

267 to enable improvement of the reefs' state and to prevent further deterioration.

268 The general notion that proactive human intervention will be critical for mankind's survival,

269 health, and prosperity, is becoming increasingly common among terrestrial ecology scientists

270 and decision-makers (Dobson et al. 1997; Suding 2011). In contrast, the mainstream scientific

271 approach does not consider restoration as an applicable management tool for coral reef

272 ecosystems (e.g. (Adger et al. 2005; Mumby \& Steneck 2008); but conversely see (Abelson et al.

273 2015; Rinkevich 2014)).

274 In this work we used a mathematical model to examine the feasibility and potential efficiency of

275 fish population restocking, aimed at accelerating coral reef recovery. The proposed 'restocking'

276 tool, as applied to fishery enhancement management, is based on previous efforts to enhance

277 wild fish populations by releasing cultured fish into aquatic environments (Leber 2013). Ideally,

278 fish from the local population would be used as the brood of the cultured fish for restocking, and

279 the brood population would be large enough to limit the loss of variability due to founder's effect

280 (Champagnon et al. 2012).

281 However, the restocking tool is not suggested as a management solution for recovery of every

282 degraded reef. It has been shown that beyond $0.5 \mathrm{~B}_{0}$ (where $\mathrm{B}_{0}$ is the average biomass of resident

283 reef fish in the absence of fishing; MacNeil et al. 2015) fishery restrictions can in themselves be 
284 successful in sustaining key functions of reef fish such as herbivory (MacNeil et al. 2015). Thus

285 we suggest that the 'restocking' restoration solution be examined in severely depleted sites, such

286 as heavily fished reefs (e.g. reefs in Jamaica, Guam and Papua New Guinea; Knowlton \&

287 Jackson 2008; MacNeil et al. 2015), which also guarantees that reintroducing fish into the reef

288 will not harm the homeostasis of the ecological system, but rather contribute to restoring it.

289 The dynamics of the grazers selected for restocking should satisfy several conditions. The

290 carrying capacity of grazers should depend on the amount of coral coverage, and increase with

291 increased coverage. In contrast, coral coverage cannot be so high that the macroalgal coverage

292 would be insufficient to support the feeding needs of the grazers. However, because the coral

293 coverage does not tend to exceed the threshold of food limitation for grazers (Blackwood et al.

294 2011), this is not a substantial limiting factor of the model's generality. To maintiain the grazers

295 at substantial quantities within the perimeter of the reef, both fishing and migration rates of the

296 grazers should not be high. While our analysis assumed complete fishing restrictions and

297 intermediate migration rates, similar results would be obtained with a low amount of fishing

298 permitted and low migration, since the fishing and migration parameters work in the same

299 manner in the model (see methods and supporting information S1). Finally, the grazers must

300 exert a grazing pressure that is sufficient to produce a significant effect on the macroalgal

301 coverage. Some of the grazers that fulfill the above assumptions are certain Parrotfish genera

302 (Mumby et al. 2006; Williams \& Polunin 2001) and siganid fish (Siganus virgatu)

303 (Plass-Johnson et al. 2015), which also seems to be a feasible taxon for culturing (Duray 1998).

304 Importantly, our results show that restocking is a financially beneficial method, due to the high

305 economic value of coral reef services (Caillaud et al. 2011; Cesar \& Van Beukering 2004) and

306 the potentially low cost of restocking (Lorenzen et al. 2013). In addition, fish restocking has the 
307 advantage that it does not require full-cover intervention of the entire reef area. Such restocking

308 is intended to be applied in spatially-limited focal spots, which will subsequently serve as

309 potential rehabilitation hotspots for further (natural) recovery of the rest of the reef area, via

310 spillover of adult grazers, or by larval supply from the restored patches as sources of 'flourishing

311 populations' (Abesamis \& Russ 2005; Selig \& Bruno 2010). Thus when the reef is clearly in a

312 more severe state, we should consider implementing additional interventions concurrently with

313 restocking. For instance, in dense macroalgae-dominated reefs, restocking can be ineffective, as

314 fish tend to remain outside dense algal forests (Hoey \& Bellwood 2011). Furthermore, some

315 grazing fish can alter their main source of nutrition in response to changes in the abundance of

316 algae types (Khait et al. 2013). If, on the other hand, macroalgae eradication alone is applied,

317 given that future research will indeed show that this is a cost-effective method of restoration, the

318 reef is expected quickly to become covered again by macroalgae due to the lack of grazers

319 (McClanahan et al. 2000). In such a situation, restocking following macroalgae eradication can

320 promote natural recruitment. Such combined interventions might prove to have synergistic

321 interactions, and to be even more efficient and economically beneficial. Another possible

322 intervention is that of coral transplantation, also termed reef gardening, in which corals are

323 directly planted into a reef (Edwards 2010; Rinkevich 2005). Although this method directly

324 increases the coral coverage and the reef's structural complexity (rugosity), it is estimated at

325 about 200,000-1,300,000 USD per km² for low-cost transplantations (Edwards \& Gomez 2007).

326 Therefore, when comparing between the two alternative restoration tools, under the

327 circumstances discussed above, even if the reef gardening method is highly effective, the

328 relatively negligible cost of restocking (estimated here at 6,000 USD per $\mathrm{km}^{2}$ ), and its potential

329 benefit should at least incentivize the implementation of both tools concomitantly. 
330 It is our expectation that future research will yield further ecological and economic estimates,

331 which could help us to assess the efficiency of such interventions and of their combinations.

332 It should be stressed that our proposed restoration approach is not presented as an alternative to

333 protection. Moreover, we agree with the widely-accepted notion that protection (including

334 removal of stressors, if applicable) is the most important management tool by which to maintain

335 reef health and to facilitate the fast recovery of reefs following wide-scale natural disturbances.

336 We propose, nonetheless, that fish restocking, and possibly other ecological restoration tools in

337 conjunction with conservations measures, be considered as an efficient and economically

338 beneficial method for the rehabilitation coral reefs. 
References

Abelson A, Halpern BS, Reed DC, Orth RJ, Kendrick GA, Beck MW, Belmaker J, Krause G, Edgar GJ, and Airoldi L. 2015. Upgrading Marine Ecosystem Restoration Using Ecological-Social Concepts. BioScience:biv171 .

Abesamis RA, and Russ GR. 2005. Density-dependent spillover from a marine reserve: long-term evidence. Ecological Applications 15:1798-1812 .

Adger WN, Hughes TP, Folke C, Carpenter SR, and Rockström J. 2005. Social-ecological resilience to coastal disasters. science 309:1036-1039.

Alvarez-Filip L ,Dulvy NK, Gill JA, Cote IM, and Watkinson AR. 2009. Flattening of Caribbean coral reefs: region-wide declines in architectural complexity. Proceedings of the Royal Society B-Biological Sciences 276:3019-3025 .

Angeler D. 2010. Biomanipulation: a useful tool for wetland rehabilitation. Ecology of Threatened SemiArid Wetlands:215-228 .

Blackwood JC, Hastings A, and Mumby PJ. 2011. A model-based approach to determine the long-term effects of multiple interacting stressors on coral reefs. Ecological Applications 21:2722-2733 .

Blackwood JC, Hastings A, and Mumby PJ. 2012. The effect of fishing on hysteresis in Caribbean coral reefs. Theoretical Ecology 5:105-114 .

Bowling T. 2014. Bumphead Breakthrough: Tank Raised Parrotfish.

Burke L, K.Reytar, M. Spalding and A.Perry. 2011. Reefs At Risk Revisited. World Resources Institute, Washington. $130 \mathrm{p}$.

Caillaud A, Damiens F, Salvat B, and Wilkinson C. 2011. Preventing coral grief: a comparison of Australian and French coral reef protection strategies in a changing climate. Sustainable Dev L \& Pol'y $12: 26$.

Castell LL, Naviti W, and Nguyen F. 1996. Detectability of cryptic juvenile Trochus niloticus linnaeus in stock enhancement experiments. Aquaculture 144:91-101 .

Cesar HS, and Van Beukering P. 2004. Economic valuation of the coral reefs of Hawai'i. Pacific Science 58:231-242.

Champagnon J, Elmberg J, Guillemain M, Gauthier-Clerc M, and Lebreton J-D. 2012. Conspecifics can be aliens too: a review of effects of restocking practices in vertebrates. Journal for Nature Conservation 20:231-241.

Cowx IG. 1999. An appraisal of stocking strategies in the light of developing country constraints. Fisheries Management and Ecology 6:21-34 .

Cowx IG, and Gerdeaux D. 2004. The effects of fisheries management practises on freshwater ecosystems. Fisheries Management and Ecology 11:145-151 .

De'ath G, Lough JM, and Fabricius KE. 2009. Declining Coral Calcification on the Great Barrier Reef. Science 323:116-119.

De'ath G, Fabricius KE, Sweatman H, and Puotinen M. 2012. The 27-year decline of coral cover on the Great Barrier Reef and its causes. Proceedings of the National Academy of Sciences 109:1799517999 .

Dobson AP, Bradshaw A, and Baker Aá. 1997. Hopes for the future: restoration ecology and conservation biology. Science $27.7: 515-522$

Duray MN. 1998. Biology and culture of siganids: Aquaculture Department, Southeast Asian Fisheries Development Center (SEAFDEC/AQD.(

Edwards AJ. 2010. Reef Rehabilitation Manual. Coral Reef Targeted Research \& Capacity Building for Management Program: St Lucia, Australia. ii + 166 pp. 
Edwards AJ, and Gomez ED. 2007. Reef Restoration Concepts and Guidelines: making sensible management choices in the face of uncertainty. Coral Reef Targeted Research \& Capacity Building for Management Programme :St Lucia, Australia. iv + 38 pp.

FAO. 2014. The State of World

Fisheries and Aquaculture

Opportunities and challenges. FOOD AND AGRICULTURE ORGANIZATION OF THE UNITED NATIONS.

Fung T, Seymour RM, and Johnson CR. 2011. Alternative stable states and phase shifts in coral reefs under anthropogenic stress. Ecology 92:967-982 .

Gaudian G, Medley P, and Ormond R. 1996. Estimation of the size of a coral reef fish population. Oceanographic Literature Review 43.

Hervas S, Lorenzen K, Shane MA, and Drawbridge MA .2010 .Quantitative assessment of a white seabass (Atractoscion nobilis) stock enhancement program in California: Post-release dispersal, growth and survival. Fisheries Research 105:237-243 .

Hoey AS, and Bellwood DR. 2011. Suppression of herbivory by macroalgal density: a critical feedback on coral reefs? Ecology letters 14:267-273.

Hughes T, Baird A, Dinsdale E, Moltschaniwskyj N, Pratchett M, Tanner J, and Willis B. 1999. Patterns of recruitment and abundance of corals along the Great Barrier Reef. Nature 397:59-63 .

Hughes TP, Graham NA, Jackson JB, Mumby PJ, and Steneck RS. 2010. Rising to the challenge of sustaining coral reef resilience. Trends in ecology \& evolution 25:633-642 .

Huntington B, Karnauskas M, and Lirman D. 2011. Corals fail to recover at a Caribbean marine reserve despite ten years of reserve designation. Coral Reefs 30:1077-1085 .

Jompa J, and McCook LJ. 2002. Effects of competition and herbivory on interactions between a hard coral and a brown alga. Journal of Experimental Marine Biology and Ecology 271:25-39.

Kaunda-Arara B, and Rose GA. 2004. Out-migration of tagged fishes from marine reef National Parks to fisheries in coastal Kenya. Environmental Biology of Fishes 70:363-372 .

Khait R, Obolski U, Hadany L, and Genin A. 2013. Food Selectivity and Diet Switch Can Explain the Slow Feeding of Herbivorous Coral-Reef Fishes during the Morning .

Knowlton N, and Jackson JB. 2008. Shifting baselines, local impacts, and global change on coral reefs. PLoS biology 6:e54 .

Leber KM. 2013. Marine Fisheries marine fisheries Enhancement marine fisheries enhancement, Coming of Age in the New Millennium. Sustainable Food Production: Springer, 1139-1157.

Lindegren M, Mollmann C, and Hansson LA. 2010. Biomanipulation: a tool in marine ecosystem management and restoration? Ecological Applications 20:2237-2248 .

Lorenzen K, Agnalt A-L, Blankenship HL, Hines AH, Leber KM, Loneragan NR, and Taylor MD. 2013. Evolving context and maturing science: Aquaculture-based enhancement and restoration enter the marine fisheries management toolbox. Reviews in Fisheries Science 21:213-221 .

Lorenzen K, Leber KM, and Blankenship HL. 2010. Responsible approach to marine stock enhancement: an update. Reviews in Fisheries Science 18:189-210 .

MacNeil MA, Graham NA, Cinner JE, Wilson SK, Williams ID, Maina J, Newman S, Friedlander AM, Jupiter $S$, and Polunin NV. 2015. Recovery potential of the world's coral reef fishes. Nature 520:341344 .

McClanahan T, Bergman K, Huitric M, McField M, Elfwing T, Nyström M, and Nordemar I. 2000. Response of fishes to algae reduction on Glovers Reef, Belize. Marine Ecology Progress Series 206:273-282 . 
430

431

432

433

434

435

436

437

438

439

440

441

442

443

444

445

446

447

448

449

450

451

452

453

454

455

456

457

458

459

460

461

462
Mumby PJ, Dahlgren CP, Harborne AR, Kappel CV, Micheli F, Brumbaugh DR, Holmes KE, Mendes JM, Broad K, and Sanchirico JN. 2006. Fishing, trophic cascades, and the process of grazing on coral reefs. science 311:98-101.

Mumby PJ, and Harborne AR. 2010. Marine reserves enhance the recovery of corals on Caribbean reefs . PLoS One 5:e8657.

Mumby PJ, Hastings A, and Edwards HJ. 2007. Thresholds and the resilience of Caribbean coral reefs. Nature 450:98-101.

Mumby PJ, and Steneck RS. 2008. Coral reef management and conservation in light of rapidly evolving ecological paradigms. Trends in ecology \& evolution 23:555-563 .

Pandolfi JM, Bradbury RH, Sala E, Hughes TP, Bjorndal KA, Cooke RG, McArdle D, McClenachan L, Newman MJH, Paredes G, Warner RR, and Jackson JBC. 2003. Global trajectories of the longterm decline of coral reef ecosystems. Science 301:955-958 .

Plass-Johnson JG, Ferse SC, Jompa J, Wild C, and Teichberg M. 2015. Fish herbivory as key ecological function in a heavily degraded coral reef system. Limnology and Oceanography .

Rinkevich B. 2005. Conservation of coral reefs through active restoration measures: Recent approaches and last decade progress. Environmental Science \& Technology 39:4333-4342 .

Rinkevich B. 2008. Management of coral reefs: We have gone wrong when neglecting active reef restoration. Marine Pollution Bulletin 56:1821-1824 .

Rinkevich B. 2014. Rebuilding coral reefs: does active reef restoration lead to sustainable reefs? Current Opinion in Environmental Sustainability 7:28-36 .

Selig ER, and Bruno JF. 2010. A global analysis of the effectiveness of marine protected areas in preventing coral loss. PLoS One 5:e9278 .

Spurgeon J. 1999. The socio-economic costs and benefits of coastal habitat restoration and creation. Special publication Phuket Marine Biological Center Phuket:133 .

Suding KN. 201 .1Toward an era of restoration in ecology: successes, failures, and opportunities ahead. Annual Review of Ecology, Evolution, and Systematics 42:465-487 .

Villanueva RD, Edwards AJ, and Bell JD. 2010. Enhancement of Grazing Gastropod Populations as a Coral Reef Restoration Tool: Predation Effects and Related Applied Implications. Restoration Ecology 18:803-809.

Williams I, and Polunin N. 2001. Large-scale associations between macroalgal cover and grazer biomass on mid-depth reefs in the Caribbean. Coral Reefs 19:358-366. 


\section{Figure legends}

464

465 Figure 1: Revenue of restocking. The expected revenue of restocking a $15 \mathrm{~km}^{2}$ reef is

466 represented by a color scale (in $\log _{10}$ scale), as a function of the reef's initial macroalgae and

467 coral coverage (horizontal and vertical axes, respectively). Note that $T=1-M-C$ and the state of

468 the algal turfs $(T)$ is defined by the other two variables. The revenue is calculated for 5 years (A)

469 and 20 years (B) after restocking has been implemented. Areas in which the revenue is negative

470 are replaced by zeros on the color scale (note that the negative revenue is bounded from below

471 by the initial cost of restocking). Black curves divide the plot into three initial condition areas: (I)

472 the system reaches a state with high coral coverage with or without restocking; (II) the system

473 reaches a high macroalgae state in the absence of intervention but high coral coverage under

474 restocking; and (III) the system reaches a state with high macroalgae coverage with or without

475 restocking. Parameter values are given in the main text.

476
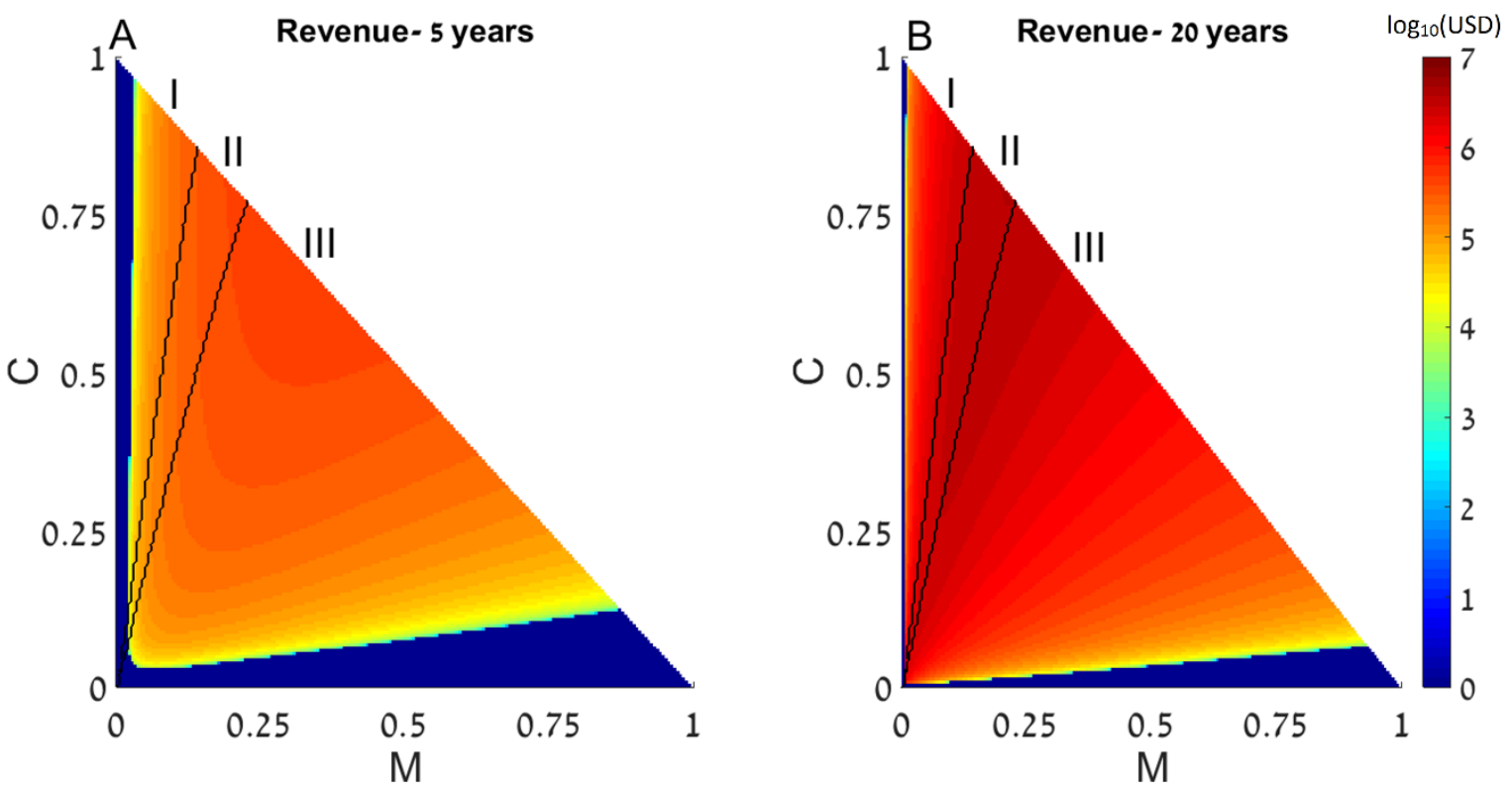
477 Figure 2: Restocking shortens restoration time. We plot the values of the coral coverage $(C$,

478 light blue), macroalgae coverage ( $M$, green), and grazing fish ( $P$, red) with respect to time, no

479 intervention (A and C), and restocking (B and D), for different initial conditions. Panels A and B

480 present the model variables simulated from initial values in which the reef will be restored

481 without intervention $\left(C_{0}=0.35, M_{0}=0.05\right)$. Panels $\mathrm{C}$ and $\mathrm{D}$ represent initial conditions in which

482 the coral reef will deteriorate without intervention, but will return to high coral coverage when

483 restocking is implemented $\left(C_{0}=0.35, M_{0}=0.07\right)$. Other parameter values are as in Fig. 1.

484
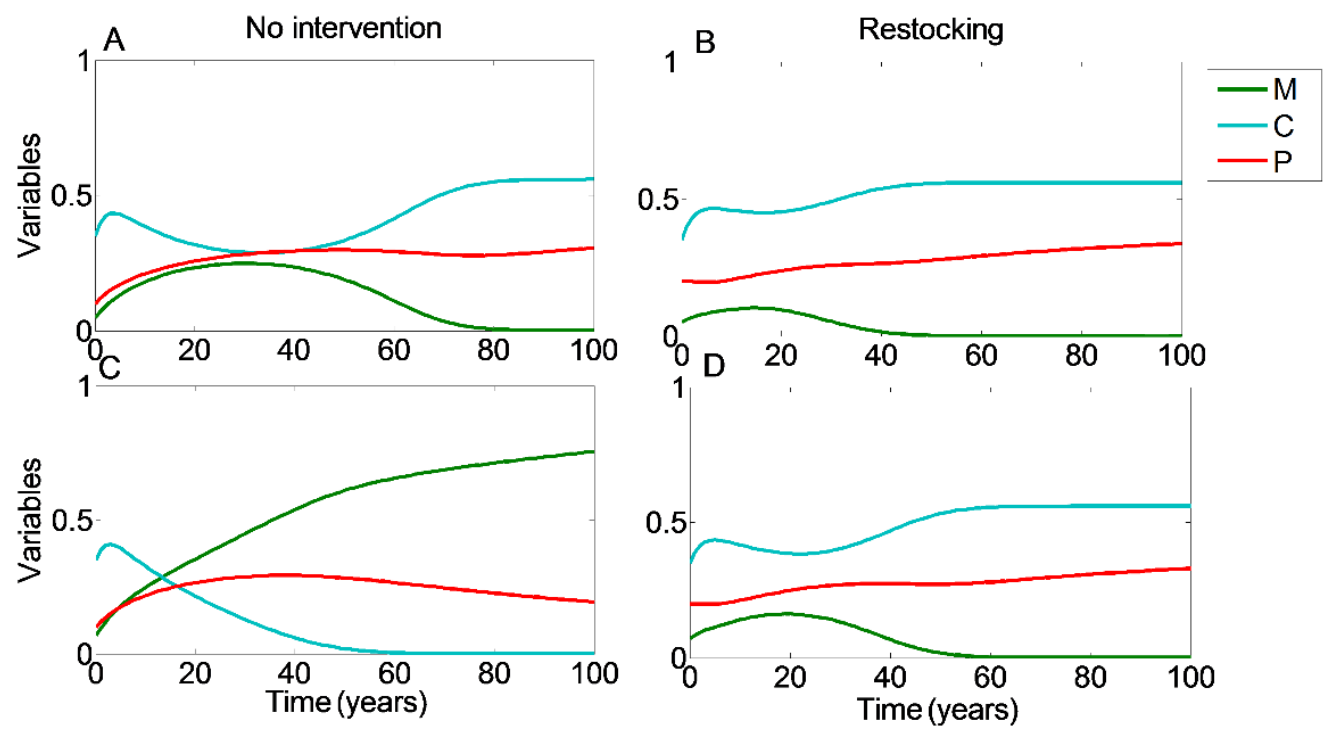
486 Figure 3: Revenue of restocking in two connected reefs. The expected revenue of restocking in

487 one reef, connected by fish migration to another reef, is represented by a color scale (in $\log _{10}$

488 scale), as a function of the reefs' initial macroalgae and coral coverage (horizontal and vertical

489 axes, respectively). Note that $T=1-M-C$ and the state of the algal turfs $(T)$ is defined by the other

490 two variables. The revenue is calculated for 5 years (A) and 20 years (B) after restocking has

491 been implemented. Areas in which the revenue is negative are replaced by zeros on the color

492 scale (note that the negative revenue is bounded from below by the initial cost of restocking).

493 Black curves divide the plot into five areas according to initial conditions leading to different

494 outcomes. The areas are marked by Roman numerals, and explained in the main text. Parameters

495 are as in Fig.1, with migrating fish from the restocked reef ending up in the other reef.
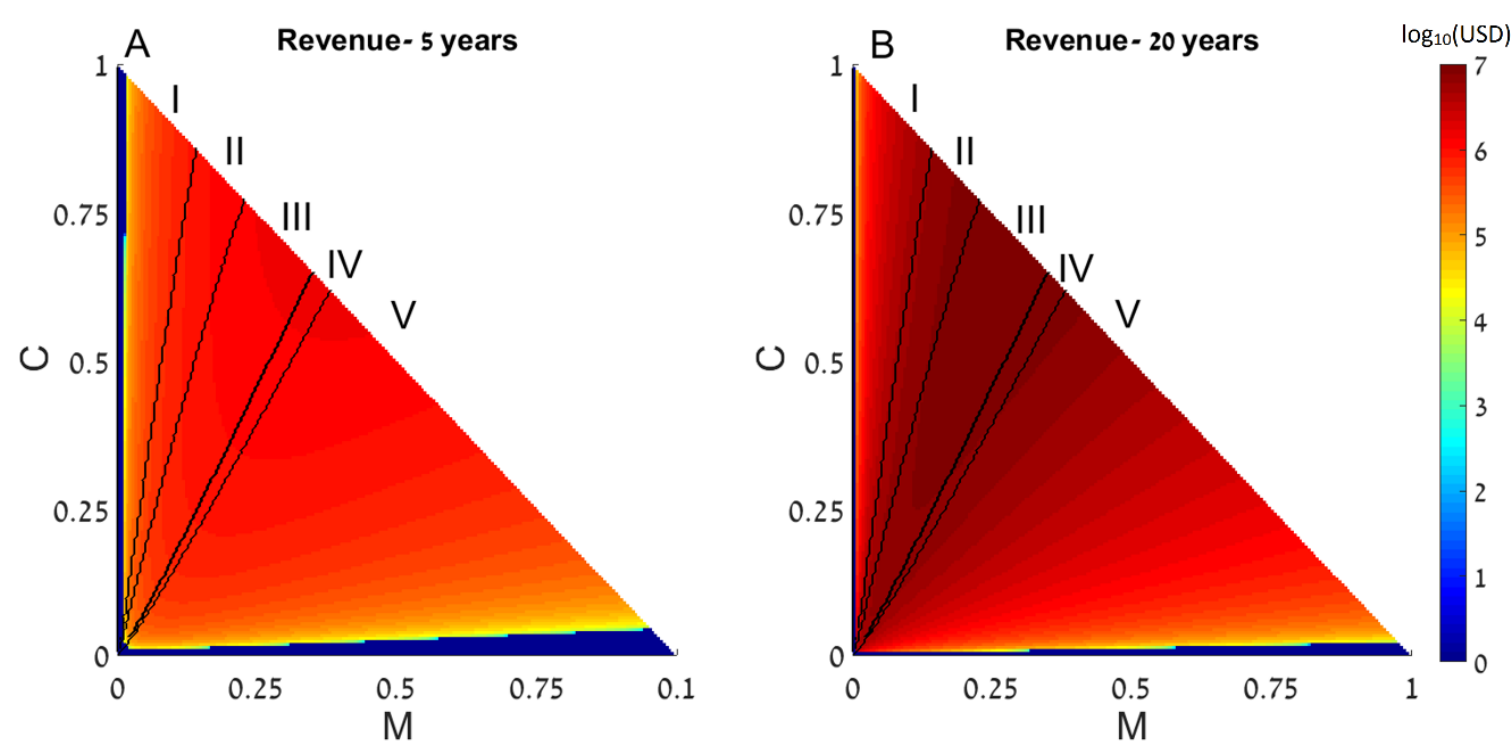
498 Figure 4: Restocking shortens restoration time in connected reefs. The model's variables the $(C$, 499 coral coverage ; $M$, macroalgae coverage; $P$, grazing fish) are plotted with respect to time, under 500 no intervention (A and C) and restocking (B and D) for two reefs connected by migration. $C_{I}, M_{I}$ $501, P_{I}$ and $C_{I I}, M_{I I}, P_{I I}$, represent the coral coverage (light blue), macroalgae coverage (green), and 502 grazing fish (red), for the upstream (dashed lines) and downstream (solid lines) reefs,

503 respectively. Panels A and B present the model variables simulated from initial values in which 504 both reefs will be restored without intervention $\left(C_{0}=0.35, M_{0}=0.05\right)$. Panels $\mathrm{C}$ and $\mathrm{D}$ represent 505 initial conditions in which the upstream coral reef will deteriorate without intervention, but will 506 return to high coral coverage when restocking is implemented $\left(C_{0}=0.35, M_{0}=0.07\right)$. Other 507 parameter values are as in Fig.3.

508

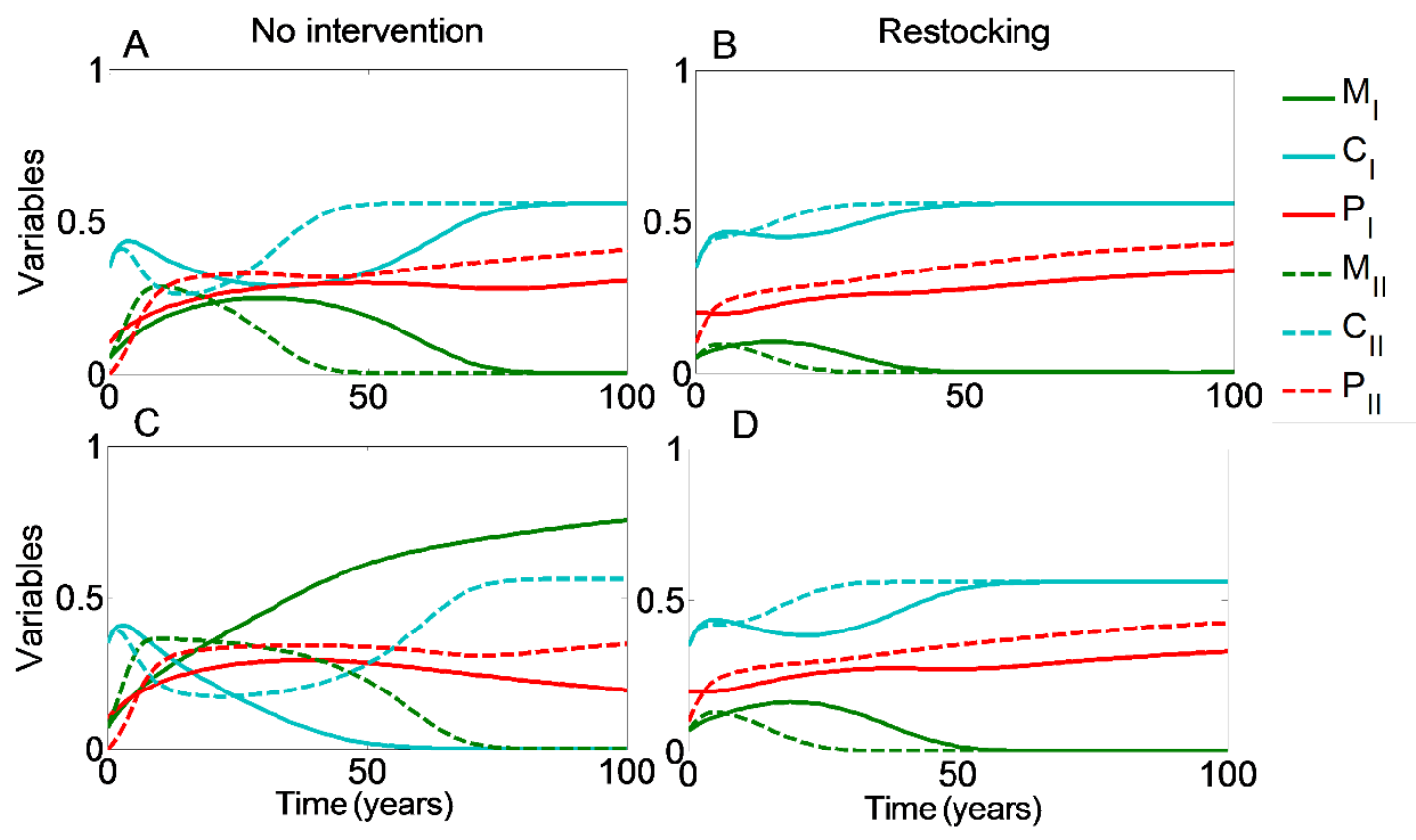


Table 1: Coral growth model parameters.

Parameter Value Meaning

\begin{tabular}{|c|c|c|}
\hline a & 0.1 & Rate of macroalgae overgrowth on corals \\
\hline$\gamma$ & 0.8 & Rate of macroalgae overgrowth on algal turfs \\
\hline $\mathrm{r}$ & 1 & Rate of coral growth on algal turfs \\
\hline d & 0.44 & Natural coral mortality \\
\hline $\mathrm{f}$ & 0 & Fishing rate of grazing fish (we assume fishing restrictions) \\
\hline $\mathrm{S}$ & 0.49 & Grazing fish growth rate \\
\hline$H_{G}, H_{E}$ & 0.03 & Growth and erosion rates of reef complexity, respectively \\
\hline $\mathrm{m}$ & 0.12 & Spillover rate \\
\hline$\delta_{p}$ & 0.1 & $\begin{array}{l}\text { Proportion of grazing fish restocked, normalized to the } \\
\text { carrying capacity }\end{array}$ \\
\hline
\end{tabular}

511

Table 2: Economic model parameters

Parameter Value Meaning

\begin{tabular}{|c|c|c|}
\hline$X$ & 15 & Coral reef size $\left(\mathrm{km}^{2}\right)$ \\
\hline $\boldsymbol{B}_{c}$ & 200,000 & Benefit of coral reef ? $\frac{U S D}{\text { year } * k m^{2}}$ ? \\
\hline $\boldsymbol{r}^{\prime}$ & 0.05 & Discount rate \\
\hline$R$ & 3000 & Estimated grazing fish carrying capacity $?_{\mathrm{km}^{2}}^{1}$ ? \\
\hline 国 & 50 & Estimated cost per fish (USD) \\
\hline
\end{tabular}

